IMAGES

\section{Reconstruction of a Posterior Trunk Defect using a Pedicled Dorsolateral Posterior Intercostal Artery Perforator Flap}

Jun Chul Shin, Jeong Hoon Song, Woo Hoe Heo

Department of Plastic and Reconstructive Surgery, Wonkwang University School of Medicine, Iksan, Korea

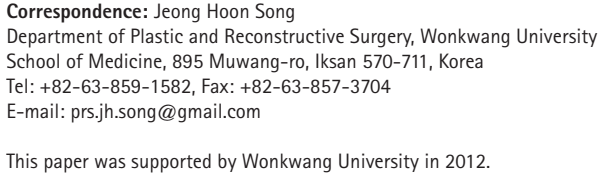

This article was presented as a poster at the 3 rd Research and Reconstruction Forum on May 9-10, 2013 in Keimyung University (Daegu), Korea.

No potential conflict of interest relevant to this article was reported.

Received: 10 Apr 2014 • Revised: 4 May 2014 • Accepted: 14 May 2014 pISSN: 2234-6163・ elSSN: 2234-6171

http://dx.doi.org/10.5999/aps.2014.41.5.598 • Arch Plast Surg 2014;41:598-600

Copyright (C) 2014 The Korean Society of Plastic and Reconstructive Surgeons This is an Open Access article distributed under the terms of the Creative Commons Attribution Non-Commercial License (http://creativecommons.org/licenses/by-nc/3.0/) which permits unrestricted non-commercial use, distribution, and reproduction in any medium, provided the original work is properly cited.

Soft tissue defects of the posterior trunk may be presented after radiation injury, chronic pressure sores, spina bifida, dehiscence with exposure of spinal stabilization devices, and postoperative wound infection, etc. [1]. According to the location, it can be divided into four anatomic territories; posterior cervical, upper thoracic, mid-thoracic, and lumbar

Initial photo shows skin necrosis measuring $7 \times 6.5 \mathrm{~cm}$ in size on the upper and mid thoracic area. area [2]. Various regional musculocutaneous flaps have played an important role in reconstruction of the posterior trunk $[1,2]$. However, they have shortcomings of sacrificing underlying muscle and donor site morbidity. Perforator flaps have recently been regarded as a good method for reconstruction of such defects $[3,4]$. Flap extendibility and less invasiveness without sacrifice of the underlying muscles have proven that pedicled perforator flap is a useful reconstructive option in these areas $[3,4]$. Prasad et al. [5] proposed the vascular anatomy of dorsolateral musculocutaneous perforators of the posterior intercostals artery (PICA). We experienced a case of pedicled dorsolateral PICA perforator V-Y advancement flap for resurfacing of the posterior trunk defect. Therefore, we report our experience and the results.

A 59-year-old male with a 10-year history of diabetes and hypertension was transferred to our department. He visited our hospital with a rapidly progressing mid thoracic abscess. First, incision and drainage was performed in another department, however, soft tissue necrosis occurred. A dark colored necrosis measuring $7 \times 6.5 \mathrm{~cm}$ in size was observed on the upper and mid-thoracic area (Fig. 1).

Debridement, antibiotic therapy, and wound care were initiated. After achieving control of the infection, we performed a one-stage reconstruction using pedicled perforator flap with a freestyle concept. After debridement, the defect measured $18 \times 14 \mathrm{~cm}$ in size (Fig. 2). Hand held Doppler was used to map the perforator.

Using $3.5 \times$ loupe magnification, careful suprafascial

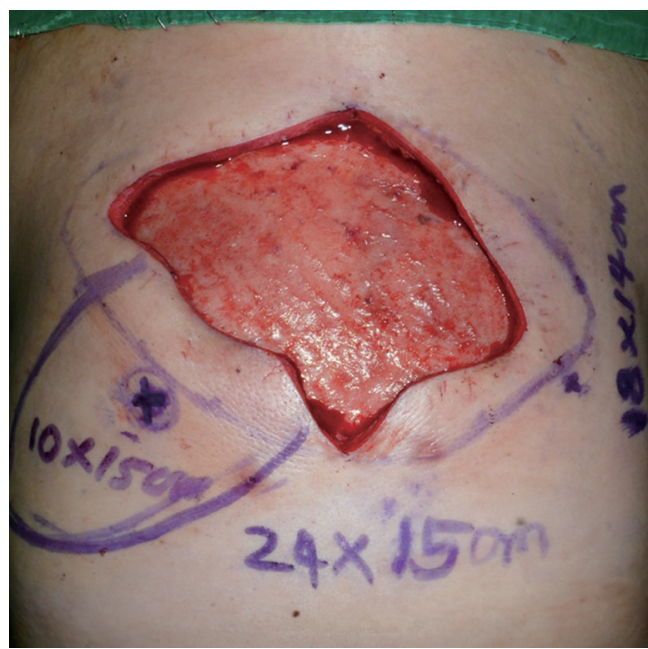

Fig. 2.

Preoperative photo, defect size was $18 \times 14 \mathrm{~cm}$ and size of the undermined area was $24 \times 15 \mathrm{~cm}$. 

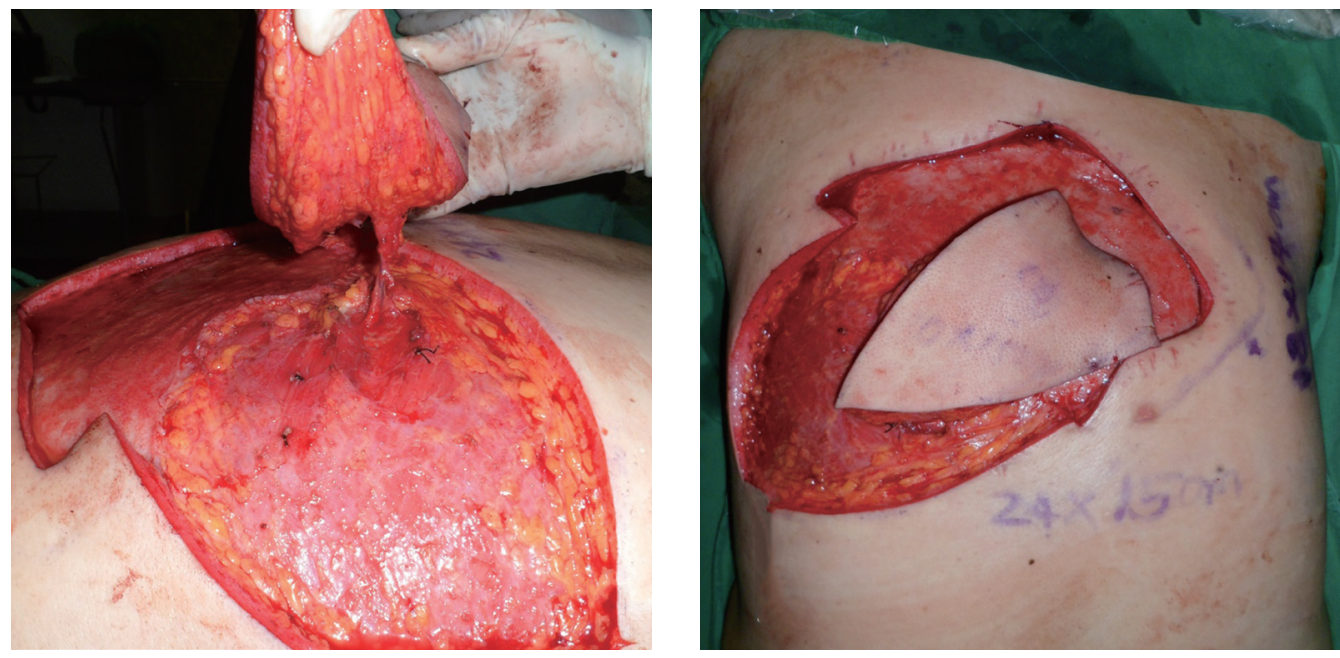

Fig. 3.

After identification of two perforators, we selected the more reliable and pulsatile perforator, and performed medial dissection of the pedicle.

dissection was performed; we then identified two perforators and selected the more reliable pulsatile perforator (Fig. 3). In order to cover the defect, we needed a longer pedicle, therefore, we dissected the pedicle medially and the flap could reach the defect area. It took one hour to elevate the flap. After the flap was insetted with V-Y advancement, the defect was covered and the donor site was closed with primary closure (Fig. 4). After the operation, we had a stable postoperative course without flap congestion. There was minimal complication, such as development of a suture marginal crust, which was treated with conservative methods. The patient was discharged at postoperative 10 days. Two months after surgery, the patient remains in good health, and has shown good healing results (Fig. 5).

Reconstruction of the posterior trunk requires careful analysis of the defect and appropriate selection of the tissue that will provide coverage while maximizing both form and function. Achievement of stable soft tissue coverage is the key to success of treatment. Latissimus dorsi and trapezius musculocutaneous flap have traditionally been the workhorse flaps $[1,2]$.

Progress in reconstructive surgery has led to refinement of standard procedures, and the concept of perforators has allowed a new dimension in reconstructive surgery. It defines the vascular supply for a skin island from a single perforator penetrating the deep muscle fascia while sparing tissues surrounding the pedicle [4]. With the understanding that any perforator can be used as a flap, use of the freestyle flaps allows for flexible design of the flap, enhancing the chance for reconstruction. After evaluation of the defect, an appropriate area adjacent to the injury site is selected and Doppler investigation and mapping are performed, followed by custommade flap design [4]. When we first elevated the flap, we performed the operation using a freestyle concept under a posterior intercostals artery anatomic basis. However, after performing the operation, we have determined that our finding is compatible with Prasad's report on dorsolateral musculocutaneous perforators of the posterior intercostals artery. Previous studies have not provided comprehensive documentation of the existence of musculocutaneous perforators of the costal segment of the PICA. However, Prasad et al. [5] first proposed that musculocutaneous perforators of the costal segment of the PICA are consistently present in intercostal spaces $8-11$. They reported that the average pedicle length of perforator is $4.6 \pm 0.4 \mathrm{~cm}$ and additional length $(6-12 \mathrm{~cm})$ could be achieved by freeing the PICA along the lower costal margin either medially or laterally. Average diameter of the PICA at the origin of the dorsolateral perforator is $1.85 \mathrm{~mm}$ (range, 1.6-2.1 mm). Perforator flap may be harvested based on the dorsolateral perforators of the PICA with preservation of the thoracodorsal artery and latissimus dorsi muscle [5].

There are many options for posterior trunk reconstruction. However, we propose that pedicled dorsolateral branch of PICA perforator flap is a good surgical option for treatment of large posterior trunk defects, which may be applied with great flexibility and can enable versatile reconstruction.
Fig. 4.

After pedicle dissection, we inset the flap with $\mathrm{V}-\mathrm{Y}$ shape and closed the donor primarily. 


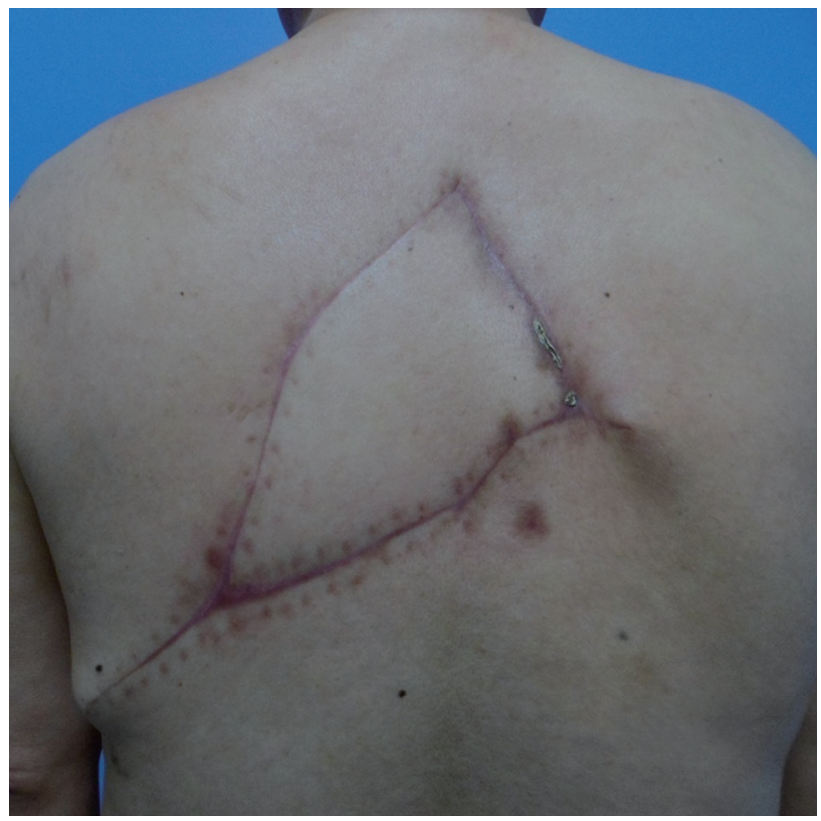

Fig. 5.

Postoperative two months, postoperative course was uneventful.

\section{References}

1. Mathes DW, Thornton JF, Rohrich RJ. Management of posterior trunk defects. Plast Reconstr Surg 2006;118:73e-83e.

2. Hallock GG. Reconstruction of posterior trunk defects. Semin Plast Surg 2011;25:78-85.

3. Hamdi M, Van Landuyt K, de Frene B, et al. The versatility of the inter-costal artery perforator (ICAP) flaps. J Plast Reconstr Aesthet Surg 2006;59:644-52.

4. Oh TS, Hallock G, Hong JP. Freestyle propeller flaps to reconstruct defects of the posterior trunk: a simple approach to a difficult problem. Ann Plast Surg 2012;68:79-82.

5. Prasad V, Almutairi K, Kimble FW, et al. Dorsolateral musculocutaneous perforators of posterior intercostal artery: an anatomical study.J Plast Reconstr Aesthet Surg 2012;65:1518-24.
Liposarcoma in the Axilla Developed from a Longstanding Lipoma

Yoon-Jae Lee, Yeon Jin Jeong, Jung Ho Lee, Young-Joon Jun, Young-Jin Kim

Department of Plastic Surgery, Bucheon St. Mary's Hospital, The Catholic University of Korea College of Medicine, Bucheon, Korea

\section{Correspondence: Jung Ho Lee}

Department of Plastic Surgery, Bucheon St. Mary's Hospital, The Catholic University of Korea College of Medicine, 327 Sosa-ro, Wonmi-gu, Bucheon 420-717, Korea

Tel: +82-32-340-7059, Fax: +82-2-594-7230

E-mail:tfm0822@catholic.ac.kr

No potential conflict of interest relevant to this article was reported.

Received: 17 Feb 2014 • Revised: 18 Apr 2014 • Accepted: 18 Apr 2014 pISSN: 2234-6163 • elSSN: 2234-6171

http://dx.doi.org/10.5999/aps.2014.41.5.600 • Arch Plast Surg 2014;41:600-602

Copyright (C) 2014 The Korean Society of Plastic and Reconstructive Surgeons

This is an Open Access article distributed under the terms of the Creative Commons Attribution Non-Commercial License (http://creativecommons.org/licenses/by-nc/3.0/) which permits unrestricted non-commercial use, distribution, and reproduction in any medium, provided the original work is properly cited. 